\title{
Study on safety and efficacy of low dose oral cyclosporine for the treatment of prurigo nodularis in Bangladeshi population
}

\author{
*Sharmeen $\mathrm{A}^{1}$, Rahman $\mathrm{MH}^{2}$, Hasan $\mathrm{MJ}^{3}$
}

\begin{abstract}
Prurigo nodularis (PN) is a disease with multiple itching nodules situated chiefly on the extremities. The disease is often persistent and the therapy is refractory. Oral cyclosporine used in moderate to severe psoriasis has shown modest improvement in the skin lesions with significant side effects. The drug is recently used in the treatment of PN with variable efficacy. The present study was therefore intended to investigate whether low dose oral cyclosporine can be preferred as an effective and safe therapy for Prurigo nodularis. This quasi-experimental study was conducted in the Department of Dermatology and Venereology of Community Based Medical College Hospital, Mymensingh, Bangladesh, over a period of 6 months between July 2016 to December 2016. A total of 96 clinically diagnosed cases of prurigo nodularis attending at the above mentioned places were consecutively included in the study. After evaluation of the baseline clinical and laboratory features of the patients, oral cyclosporine was given as $2 \mathrm{mg} / \mathrm{kg} /$ day for consecutive 12 weeks. A female preponderance was observed in the study with female to male ratio being 7:3. The putative etiological factors present among the patients were a history of frequent mosquito bite $(43.8 \%)$, anaemia $(28 \%)$, hypertension $(27.1 \%)$ bronchial asthma $(22.9 \%)$, family history of PN $(29.2 \%)$ and family history of atopy (24\%). The nodules were mainly distributed in front of the lower limbs followed by upper limbs and trunk. In terms of nodule characteristics, $33.3 \%$ were excoriated, $38.5 \%$ were palpable, $26 \%$ flattened, $28.1 \%$ infected and $35.4 \%$ pruritic nodules In the present study, majority $(87.5 \%)$ of the patients became free from visible lesions after 12 weeks of treatment with cyclosporine. Serum IgE and total eosinophil count reduced significantly after treatment than those before treatment $(177.5$ vs. $91.6 \mathrm{U} / \mathrm{mL}, p<0.001$ and 0.5 vs. $0.3 \mathrm{k} / \mu \mathrm{L}, \mathrm{p}<0.001$ respectively. However, $8.2 \%$ of the patients exhibited albuminuria during the course of treatment. Most of the patients of Prurigo Nodularis after 12 weeks of treatment with low-dose oral cyclosporine became free from the lesions without any significant side-effects.
\end{abstract}

CBMJ 2018 January: vol. 07 no. 01 P: 16-23

Keywords: Prurigonodularis, Cyclosporine, Itching, Skin disease

\section{Introduction}

Prurigo nodularis (PN) means "bumps that are itchy". The disease is also known as Hyde Prurigo Nodularis, PN, Lichen Simplex Chronicus, Picker Nodules, Lichen Corneus Obtusus, and Neurodermatitis Circumscripta in an atypical nodular form. The middle-aged to elderly persons are often affected with this kind of skin disease. It is recognized as a chronic inflammatory dermatosis or skin disease that results to papulo nodular eruption. Scichilone et al. found this eruption to exhibit a characteristic of pruritus in a severe form, nodules and papules with ulcerations and excoriations because of too much scratching. ${ }^{1}$

The status of PN leads to a chronic inflammatory dermatosis where a linear arrangement is commonly seen. Course is chronic and the lesions evolve slowly. The itching is severe and confined to the lesions only. Bouts of extreme pruritus often occur when these patients are under stress. From clinical observation the dermatologists find pruritus to occur characteristically

1. Dr. Atia Sharmeen Junior Consultant, Department of Dermatology and Venereology, Community Based Medical College Bangladesh

2. Prof.Dr.Muhammad Hasibur Rahman Professor \& Head

Department of Dermatology and Venereology. Community Based Medical College Bangladesh

3. Dr. Mahmud Javed Hasan

Associate professor and Head Department of Nephrology, Community Based Medical College Bangladesh

Address of correspondence:

Email:dratiashimu@gmail.com

Mobile: 01747700556 
paroxysmal intermittent, unbearably severe which is relieved only by scratching to the points of damaging the skin, usually inducing bleeding followed by scarring. ${ }^{2}$

Several studies described that the principal etiology of Prurigo Nodularis is still obscured. ${ }^{3}$ These authors noticed multiple factors that may be attributed to the occurrence of disease. These factors, among others, include i) atopic dermatitis, ii) anaemia, iii) hepatic diseases (including hepatitis C), iv) HIV disease, v) pregnancy, vi) renal failure, vii) lympho proliferative disease, viii) photo dermatitis, ix) gluten enteropathy, $\mathrm{x}$ ) stress and $\mathrm{xi}$ ) insect bites. Besides these factors Gergen et al. recorded other factors which include fungal infections, poor diet, toxin, allergic disorders, poor liver function, psychiatric illness such as delusion of parasitosis, thyroid disease, $\lg A$ dermatosis (autoimmune blistering disease) and becker's nevus. ${ }^{4}$

Dermatological diseases form an important chunk of disorders in any major hospital in our country. Skin diseases are also influenced by various factors like environment, economy, literacy, racial and social customs. The pattern of skin diseases varies from one country to another and in various regions within the same country. Prurigo nodularis presentations can be confusing and are often difficult to diagnose for dearth of dermatology experts in our country. Various modalities of treatment of $\mathrm{PN}$ are also being practiced but sometimes the disease becomes refractory to treatment. In view of this fact it is a challenge for both physicians and the individual patient concerned in dealing with their PN. So primary care physicians need an accurate guidance for diagnosing the disease, while the individual patients need accurate and succinct information and counseling from the physicians. Although cyclosporine at doses of $3-4.5 \mathrm{mg} / \mathrm{kg} / \mathrm{day}$ is used to treat recalcitrant $\mathrm{PN}$, but no study has yet been performed supporting its efficacy and safety in the context of our population. Faced with this backcloth, it is of utmost importance to undertake a study on the safety and efficacy of low-dose cyclosporine on patients suffering from PN visiting the Community Based Medical College Hospital, Mymensingh, Bangladesh with the oral Cyclosporine at doses of $2 \mathrm{mg} / \mathrm{kg} /$ day. The findings derived from present study will help us in developing an individualized treatment scheme using oral cyclosporine therapy.

\section{Methods}

The study was conducted in the Department of Dermatology \& Venereology of Community Based Medical College Hospital, Mymensingh, Bangladesh, over a period of 6 months between July 2016 to December 2016.

The demographic variables included in the studied were age, sex, marital status and occupation. History of frequent mosquito bite, bronchial asthma, family history of prurigo nodularis, family history of atopy, anaemia, hirsutism and blood pressure, known systemic and dermatological diseases and allergies, predisposition for atopic dermatitis, were sought as these conditions or factors were often associated with the disease. The local examination of skin lesions was performed in 1st visit followed by the laboratory investigations* (Hb\%, ESR, PBF, RBS, Serum creatinine, serum IgE, total eosinophil count and urine $\mathrm{R} / \mathrm{M} / \mathrm{E})$. Treatment was started with lowdose cyclosporine (at doses of 2 $\mathrm{mg} / \mathrm{kg} /$ day), although some recent studies have used it as $3-6 \mathrm{mg} / \mathrm{kg} /$ day. The clinical improvement was noted in the 2nd and 3rd visits after 6 and 12 weeks respectively. If complained by the patients or seen at follow up visits were recorded on data-sheet.

A semi-structured questionnaire (research instrument) was developed containing all the variables of interest which was finalized following pretesting. Data were collected by interview, observation and clinical examination.

*Hb: Hemoglobin; ESR: Erythrocyte Sedimentation Rate; PBF: Peripheral Blood Film; RBS: Random Blood

Sugar;Urine R/M/E: Urine Routine Microscopic Examination 
Data were processed and analyzed using software SPSS (Statistical Package for Social Sciences) version 22.0. The test statistics used to analyze the data were descriptive statistics, Paired-sample t-test and McNemar Chi-square Test. For all analytical tests, the level of significance was set at 0.05 and $p<0.05$ was considered significant. The summarized data were presented in the form tables and charts.

\section{Results}

A total of 96 patients of prurigo nodularis attending in the department of Dermatology \& Venereolgy of Community Based Medical College Hospital, Mymensingh were enrolled in the study. The majority of population was in the age group 15-50 years.

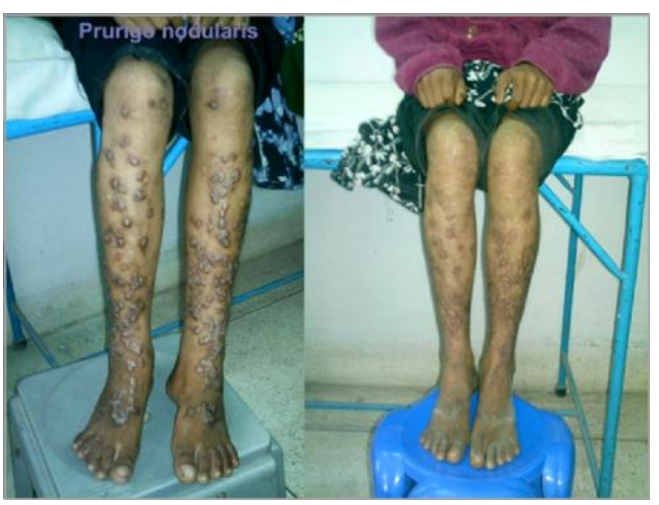

Figure 1 (a) Prurigo nodularis of lower limbs before low doses oral cyclosporine treatment. (b) after 6 weeks of low doses oral cyclosporine treatment.

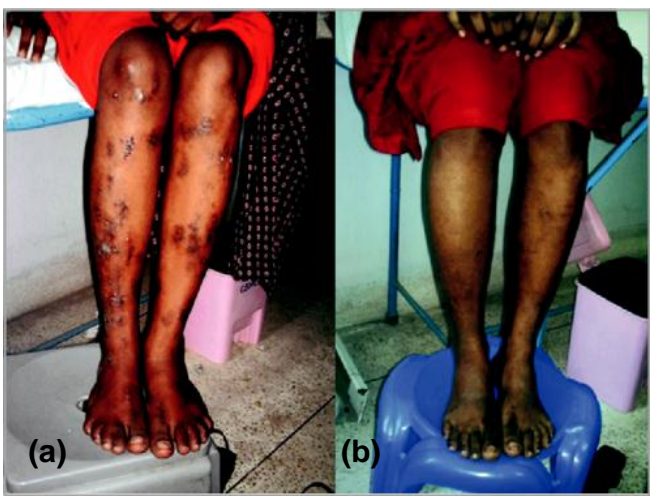

Figure 2: (a) Prurigo nodularis of lower limbs before low doses oral cyclosporine treatment. (b) after completion of low doses oral cyclosporine treatment in same patient.
Table I shows the demographics of the patients. Over half $(56.3 \%)$ of the patients was between 15 - 30 years, $21.9 \%$ between 31 - 40 years, $16.6 \%$ between 41 - 50 years and rest $5.2 \%>50$ years old. The mean age of the patients was $33.1 \pm 10.7$ (range:15-65) years.

Majority $(72 \%)$ of the patients was female having a male to female ratio of roughly $7: 3$ (Fig. 1). Over half $(54.2 \%)$ of the patients was of normal weight in terms of Body Mass Index. About $21 \%$ of patients were underweight and $25 \%$ overweight or obese. Educational status of the patients shows that $21.9 \%$ was illiterate. About $37 \%$ of the patients was primary level educated, $27.1 \%$ SSC, $11.4 \% \mathrm{HSC}$ and the remaining $3.1 \%$ graduate and higher level educated (Table I).

Table I. Distribution of patients by their demographic characteristics $(n=96)$

\begin{tabular}{|lcc|}
\hline $\begin{array}{l}\text { Demographic } \\
\text { ariables }\end{array}$ & Frequency Percentage \\
\hline Age $^{\text {\# }}$ (years) & & \\
\hline $15-30$ & 54 & 56.3 \\
$31-40$ & 21 & 21.9 \\
$41-50$ & 16 & 16.6 \\
$>50$ & 05 & 5.2 \\
\hline Sex & & \\
\hline Male & 69 & 72.0 \\
\hline Female & 27 & 28.0 \\
\hline BMI (kg/m ${ }^{2}$ ) & \\
\hline$<18.5$ (Underweight) & 20 & 20.8 \\
\hline 18.5 - 24.9 (Normal) & 52 & 54.2 \\
\hline$\geq 25$ (Overweight \& obese) & 24 & 25.0 \\
\hline Educational status & & \\
\hline Illiterate & 21 & 21.9 \\
\hline Primary & 35 & 36.5 \\
\hline SSC & 26 & 27.1 \\
\hline HSC & 11 & 11.4 \\
\hline Graduate \& above & 03 & 3.1 \\
\hline
\end{tabular}

\# Mean age $=(33.1 \pm 10.7)$ years;

range $=(15-65)$ years

The factors or clinical conditions present in patients of prurigo nodularis were a history of frequent mosquito bite $(43.8 \%)$, anaemia (28\%), hypertension (27.1\%) bronchial asthma $(22.9 \%)$, smoking habit $(9.3 \%)$, family history of prurigo nodularis (29.2\%), family history of atopy (24\%) and hirsutism (18.1\%) (Table II). 
Table II. Distribution of patients by comorbidities \& associated factors of prurigo nodularis $\left(\mathrm{n}=96^{*}\right)$

\begin{tabular}{|l|l|l|}
\hline $\begin{array}{l}\text { Co-morbidities \& } \\
\text { associated factors }\end{array}$ & Frequency & Percentage \\
\hline H/O frequent mosquito bite & 42 & 43.8 \\
Anaemia & 27 & 28.1 \\
Hypertension & 26 & 27.1 \\
Bronchial asthma & 22 & 22.9 \\
Smoking habit & 9 & 9.3 \\
Family H/O prurigo & 28 & 29.2 \\
nodularis & & \\
Family H/O atopy & 23 & 24.0 \\
Hirsutism & 18 & 18.1 \\
\hline
\end{tabular}

${ }^{*}$ Total is not correspond $100 \%$, because several factors appeared in one individual patient.

The nodules were mainly distributed in front of the lower limbs followed by upper limbs and trunk. In terms of nodule characteristics, $33.3 \%$ were excoriated, $38.5 \%$ were palpable,

$26 \%$ flattened, $28.1 \%$ infected and $35.4 \%$ pruritic nodules (Table III).

Table III. Distribution of patients by local examination $(n=96)$

\begin{tabular}{|l|l|l|}
\hline Local examination & Frequency & Percentage \\
\hline Excoriated nodules & 32 & 33.3 \\
Palpable nodules & 37 & 38.5 \\
Flattened nodules & 25 & 26.0 \\
Infected nodules & 27 & 28.1 \\
Itching & 34 & 35.4 \\
\hline
\end{tabular}

Table IV. Distribution of patients by clinical improvement $(n=96)$

\begin{tabular}{|l|l|l|}
\hline \multirow{2}{*}{ Evaluation } & \multicolumn{2}{|l|}{ Follow up } \\
\cline { 2 - 3 } & $\mathbf{1}^{\text {st }}$ visit & $\mathbf{2}^{\text {nd }}$ visit \\
\hline $\begin{array}{l}(-1) \text { Worse with new } \\
\text { lesion appear }\end{array}$ & $4(4.2)$ & 00 \\
\hline$(0)$ No improvement & 00 & 00 \\
\hline $\begin{array}{l}\text { (+1) Reduction of } \\
\text { number and size of } \\
\text { nodules Flattening of }\end{array}$ & $15(15.6)$ & $4(4.2)$ \\
\hline $\begin{array}{l}\text { (+2) } \\
\text { nodules \& reduction of } \\
\text { itching Non palpable }\end{array}$ & $28(29.2)$ & $4(4.0)$ \\
\hline $\begin{array}{l}\text { (+3) Non \& Itching } \\
\text { nodules \& no } \\
\text { but visible lesion }\end{array}$ & & \\
\hline $\begin{array}{l}\text { (+4) No visible lesion } \\
\text { Mean } \pm \text { SD } 00\end{array}$ & $84(87.5)$ \\
\hline
\end{tabular}

Table IV demonstrates the comparative evaluation of patients after 6 weeks and after 12 weeks following cyclosporine treatment. During the first 6 weeks of treatment $4.2 \%$ of patients continued to develop new lesions, but during the second 6 weeks of treatment none of the patients exhibited any new lesions. The proportion of patients with number and size of nodules, flattening of nodules, number of non-itching, non-palpable but visible lesions were reduced gradually during the 12 weeks course of treatment. Majority (87.5\%) of the patients did not have any visible lesions at the endpoint of treatment with mean evaluation score being raised from $2.0 \pm 0.9$ at 1 st visit to $3.8 \pm 0.7$ at 2 nd visit $(p<$ 0.001).

Table V. Comparison of safety and efficacy parameters before and after intervention $(n=$ 96)

\begin{tabular}{|c|c|c|c|}
\hline $\begin{array}{l}\text { Investigation } \\
\text { findings }\end{array}$ & $\begin{array}{l}\text { Before } \\
\text { treatment }\end{array}$ & $\begin{array}{l}\text { After } \\
\text { treatment }\end{array}$ & $\begin{array}{l}\mathbf{P} \\
\text { value }\end{array}$ \\
\hline $\begin{array}{l}\text { Haemoglobin } \\
(\mathrm{gm} / \mathrm{dl})^{\#}\end{array}$ & $11.5 \pm 1.3$ & $11.0 \pm 1.1$ & 0.201 \\
\hline $\operatorname{ESR}(\mathrm{mm})^{\#}$ & $27.9 \pm 12.7$ & $26.9 \pm 10.8$ & 0.106 \\
\hline RBS $(\mathrm{mmol} / \mathrm{L})^{\#}$ & $6.0 \pm 1.1$ & $6.5 \pm 0.9$ & 0.034 \\
\hline $\begin{array}{l}\text { Serum creatinine } \\
(\mathrm{mg} / \mathrm{dl})^{\#}\end{array}$ & $0.8 \pm 0.2$ & $0.9 \pm 0.2$ & 0.012 \\
\hline Serum lgE $(\mathrm{U} / \mathrm{ml})^{\#}$ & $177.5 \pm 47.3$ & $91.6 \pm 9.3$ & $<0.001$ \\
\hline $\begin{array}{l}\text { Total eosinophil } \\
\text { count }(\mathrm{k} / \mu \mathrm{L})^{\#}\end{array}$ & $0.5 \pm 0.1$ & $0.3 \pm 0.1$ & $<0.001$ \\
\hline $\begin{array}{l}\text { \# Data } \\
\text { sample t-t } \\
\text { mean } \pm \text { SD. }\end{array}$ & $\begin{array}{l}\text { analyzed } \\
\text { and were }\end{array}$ & $\begin{array}{l}\text { using } \\
\text { prese }\end{array}$ & $\begin{array}{l}\text { aired- } \\
\text { ed as }\end{array}$ \\
\hline
\end{tabular}

Comparison of safety and efficacy variables before and after treatment is shown in Table V. No significant difference was observed in hemoglobin level and ESR before and after treatment $(p=0.201$ and $p=0.106)$. Random blood sugar (RBS) and serum creatinine increased significantly from their baseline figures, but they were within normal range ( $p=0.034$ and $p=0.021$ respectively). However, serum $\operatorname{lgE}$ and total eosinophil count reduced significantly after treatment than those before treatment (177.5 vs. 91.6 $\mathrm{U} / \mathrm{mL}, \mathrm{p}<0.001$ and 0.5 vs. $0.3 \mathrm{k} / \mu \mathrm{L}, \mathrm{p}<$ 0.001 respectively.

Table VI shows the side-effects encountered by the patients of cyclosporine therapy. The 
predominant side-effect complained by the patients was headache $(51 \%)$, followed by hyperpigmentation (38.5\%), hypertrichosis $(28.1 \%)$ and hypertension (23.9\%). The less common side-effects were diarrhoea $(17.7 \%)$, blurring of vision (16.7\%), skin rash (13.5\%), gum hypertrophy $(5.2 \%)$ and muscle pain $(3.1 \%)$.

Table VI. Distribution of patients by side effects of cyclosporine $\left(n=96^{*}\right)$

\begin{tabular}{|l|c|c|}
\hline Side effects & Frequency & Percentage \\
\hline Headache & 49 & 51.0 \\
\hline Nausea and vomiting & 12 & 12.5 \\
\hline Diarrhoea & 17 & 17.7 \\
\hline Hyperpigmentation & 37 & 38.5 \\
\hline Hypertrichosis & 27 & 28.1 \\
\hline Hypertension & 23 & 23.9 \\
\hline Blurring of vision & 16 & 16.7 \\
\hline Muscle pain & 03 & 3.1 \\
\hline Skin rash & 13 & 13.5 \\
\hline Gum hypertrophy & 05 & 5.2 \\
\hline
\end{tabular}

*Total will not correspond $100 \%$, for multiple occurrences of side-effects in one individual

Majority of the patients did not exhibit albuminuria before and after treatment ( $91.7 \%$ before and $73.9 \%$ after treatment). Only $8 \%$ of patients exhibited albuminuria after 12 weeks of treatment $(7.2 \% 1+$ and $1 \% 2+)$. The difference was statistically significant $(p=0.001)$ (Table VII).

Table VII. Presence of albumin in the urine of the patients $(n=96)$

\begin{tabular}{|l|c|c|c|}
\hline Urine albumin & $\begin{array}{c}\text { Before } \\
\text { treatment }\end{array}$ & $\begin{array}{c}\text { After } \\
\text { treatment }\end{array}$ & $\begin{array}{c}\mathbf{P} \\
\text { value }\end{array}$ \\
\hline Nil & $88(91.7)$ & $71(74.0)$ & \\
\hline Trace & $8(8.3)$ & $17(17.7)$ & 0.001 \\
\hline+ and ++ & 00 & $8(8.3)$ & \\
\hline
\end{tabular}

Table VIII shows the changes in lipid profiles after 12 weeks of intervention with low-dose oral cyclosporine treated in prurigo nodularis patients. The proportions of patients with raised triglyceride and raised serum LDL were significantly higher after treatment compared to the patients before treatment $(13.5 \%$ vs. $6.3 \%, p=0.016$ and
$3.1 \%, p=0.063$ respectively). Serum cholesterol did not assume any significant change during the period $(p=0.490)$.

Table VIII. Evaluation of serum lipids before and after treatment $(n=96)$

\begin{tabular}{|l|c|c|c|}
\hline $\begin{array}{l}\text { Lipid } \\
\text { profile }\end{array}$ & $\begin{array}{l}\text { Before } \\
\text { treatment }\end{array}$ & $\begin{array}{l}\text { After } \\
\text { treatment }\end{array}$ & P-value \\
\hline $\begin{array}{l}\text { Raised serum } \\
\text { Cholesterol } \\
(\geq 200 \mathrm{mg} / \mathrm{dl})\end{array}$ & $5(5.2)$ & $7(7.3)$ & 0.490 \\
\hline $\begin{array}{l}\text { Raised } \\
\text { serum } \\
\begin{array}{l}\text { Triglyceride } \\
(\geq 180 \\
\text { mg/dl) }\end{array}\end{array}$ & $6(6.3)$ & $13(13.5)$ & 0.016 \\
\hline $\begin{array}{l}\text { Raised } \\
\text { serum LDL } \\
(\geq 100 \mathrm{mg} / \mathrm{dl})\end{array}$ & $3(3.1)$ & $8(8.3)$ & 0.063 \\
\hline
\end{tabular}

${ }^{*}$ McNemar test was done to analyze the data.

\section{Discussion}

Prurigo nodularis (PN) is a skin disease with chronic pruritic condition that decreases the quality of life of a patient. PN may exist in around $50 \%$ of cases as an overlap syndrome with atopic dermatitis (AD). Due to lack of data and randomized controlled trials, its etiology has not been clearly established and that's why thetreatment of $\mathrm{PN}$ is challenging. ${ }^{5}$ The findings of the study presented in the result section are discussed with other studies at home and abroad and all the variables of interest are reviewed chronologically.

The patients included in this study showed a female preponderance (female:male ratio 7:3). The predominant age group was 15-30 year with mean age of the patients being $33.1 \pm 10.7$ years (range: 15 - 65 years) indicating that the peak age incidence being is 2nd and 3rd decades of life. Leung et al. also found a similar male to female ratio for the PN patients but their mean age was somewhat higher $45.9 \pm$ 12.3 years. ${ }^{6}$ Sik et al. in their study however, reported a male preponderance (male to female ratio: $2: 1)^{7}$

Prurigo nodularis can occur at any age but mainly in adults between the age group of 2060 years and both sexes are equally 
affected. ${ }^{8}$ Although women are thought to be more affected by this condition, there is no strong supporting evidence in favour of this belief. Although it may develop in any age group, it is more common among young adult in this study.

Although the exact cause of Prurigo nodularis is not known, autoimmunity and genetic factors seem to play role in the development of this disease. Many of the patients present with a personal or family history of eczema or atopic dermatitis, asthma or hay fever or some allergic disorders or with comorbidities like chronic kidney diseases, anemia due to iron deficiency or metabolic disorders such as intolerance to protein (called as gluten enteropathy), HIV infection, psoriasis, Lichen Planus etc. (Michael \& Stephen, 2005). ${ }^{9} \quad$ The present study data demonstrated that history of frequent mosquito bite was common (43.8\%), followed by anaemia (28\%), hypertension $(27.1 \%)$ bronchial asthma (22.9\%). Of the family and personal history, family history of prurigonodularis was significant (29.2\%). Family history of atopy was no less (24\%). Berth-Jones reported that causes of prurigonodularis is unknown. ${ }^{10}$ However, multiple factors may contribute, which among others include atopic dermatitis, anemia, hepatic diseases (including hepatitis C), HIV disease, pregnancy, renal failure, lymphoproliferative disease, photodermatitis, gluten enteropathy, stress and insect bites. Similar findings were reported by Priya et al. with history of frequent mosquito bite and hypertension were the common associated conditions of prurigo nodularis. ${ }^{11}$

In the present study, majority $(87.5 \%)$ of the patients became free from visible lesions after 12 weeks of treatment Cyclosporine with mean evaluation score being raised from 2.0 at baseline to 3.8 at endpoint of the study indicating that low-dose oral cyclosporine is effective in the treatment of $\mathrm{PN}$. The significant reductions of serum $\lg \mathrm{E}$ and total eosinophil count at the endpoint of treatment further fortifies the efficacy of cyclosporine. The drug is well-tolerated as is evidenced by the data of safety profile obtained from the study. The level of haemoglobin did not change significantly. Random blood sugar and serum creatinine though increased, they both were within normal physiological range. However, $8 \%$ of the patients exhibited albuminuria during 12 weeks of treatment indicating the drug may indicate kidney function. All these findings explain that the drug cyclosporine is safe for long-term use. However, its judicious use is suggested for the renal impairment patients. Anon reported the findings fairly comparable with those of the present study but in his study serum creatinine increased by 0.34 $\mathrm{mg} / \mathrm{dl}$ at the end of treatment indicating that the drug is not friendly to kidney. ${ }^{12}$

Cyclosporine is generally considered to be nonmyelotoxic, but it has been reported to produce anemia in patients with juvenile-onset diabetes mellitus. ${ }^{13}$ In their study, mean hemoglobin levels decreased, but serum creatinine level and RBS rose during treatment which contrasts with the findings of the present study. According to the investigation reported by Bunikowski et al., the level of serum $\lg \mathrm{E}$ didn't change after treatment with Cyclosporine. $^{14}$ However, another report showed that Cyclosporine treatment was associated with down-regulation of $\lg \mathrm{E}$ production via suppressing the secretion of such Th2 cytokines as IL-4 and IL-5. ${ }^{15}$

These results agree well with the findings of our study. Nodular prurigo is a distressing disease which is difficult to treat. In our investigations excoriated, palpable, flattened, infected nodules and itching were commonly present on lower limb. We also showed that at the end of treatment, the mean evaluation score increased from 2.0 to 3.8 which agrees well with the findings of Berth-Jones who reported a considerable improvement of the disease (reduction in the severity of pruritus) $(n=96)$ after being treated with cyclosporine for a period of 12 weeks using low dose oral cyclosporine of $2 \mathrm{mg} / \mathrm{kg}$ per day. ${ }^{10}$ Orlando et al. also reported that improvement in pruritus and decrease in nodules treated with oral 
cyclosporine of $2 \mathrm{mg} / \mathrm{kg}$ daily. ${ }^{16}$ They reported a case of a 52 year old woman with a history of widespread, persistent and intensely pruritic lesions on all extremities and a histological diagnosis of "prurigo nodularis". The case was successfully treated with low-dose cyclosporine with any significant side effects. They consider lowdose cyclosporine a treatment of choice in the treatment of prurigo. The side-effects like hyperpigmentation and hypertrichosis that occurred in our study gradually resolved after completion of treatment. Mathews et al. reported that $86 \%$ of their patients reported three or more side effects, and $57 \%$ reported six or more with most common adverse symptoms being blurring of vision, headache, hypertension followed by hyperpigmentation. ${ }^{17}$ Ozyazgan \& coworkers also observed a high incidence of side effects with peripheral burning or discomfort, fatigue, hirsutism and headache being the most problematic. ${ }^{18}$

The values of serum lipid in prurigo nodularis patients have been studied since almost half a century ago. Lee and colleagues reported increased serum lipid concentrations in patients with prurigo nodularis. ${ }^{15}$ Since then, much research has been performed in this area, most of which consistently pointed to a raised prevalence of lipid abnormalities in individuals diagnosed with prurigo nodularis. Inspite of an increasing number of studies dealing with serum lipid levels in patients with prurigo nodularis, the results are still conflicting. ${ }^{19}$ It is still controversial whether changes in lipid composition is due to the disease itself or it is the result of medications such as cyclosporine. ${ }^{20}$

In this study, patients with raised serum triglyceride and serum LDL were significantly higher after treatment compared to the patients before treatment. The results of previous studies were greatly variable. ${ }^{3}$ These discrepancies in data from different studies may be due to the fact that patients included in statistical analysis were different phases and forms of prurigo nodularis and underwent varioustreatments before being included in the present study. The other causes may be a result of differences in lipid referential values for sex and age, which might have considerable influences on the outcome. Different methods used in disease scoring and laboratory assessment may be another cause of the discrepancy. ${ }^{21}$

\section{Conclusions}

From the findings of the present study, it can be concluded that majority of the patients of PN after 12 weeks of treatment with low-dose oral cyclosporine (2 mg/kg/day) becomes free from the lesions without any significant sideeffects. The significant reductions of serum $\lg \mathrm{E}$ and total eosinophil count at the endpoint of treatment goes in favour of its efficacy. The drug is well-tolerated except that it induces albuminuria in some patients. All these findings recommend that the drug cyclosporine is effective and safe for long-term use. However, caution is advised about its use in case of PN with known renal impairment.

\section{Recommendations}

In the light of the findings of the study and discussion thereof, the following recommendations are put forward:

1. The patients PN undergoing cyclosporine treatment need to be monitored carefully with regular laboratory evaluations and regular formal assessment of patient tolerance.

2. Further large-scale multicenter study is to be conducted before its authentic inclusion in the treatment of PN.

\section{References}

1. Scichilone $N$, Callari A, Augugliaro G, Marchese M, Togias A \& Bellia V. The impact of age on prevalence of positive skin prick tests and specific lgE tests. Respir Med. 2011;105(5):651-658.

2. James WD, Berger TG, Elston D,editors. Andrews' diseases of skin, Clinical Dermatology. 20th ed. Saunders Elsevier; 2006. 
Original Article

3. Fleischer $A B$, editor. The clinical management of itching. New York: Parthenon Publishing; 2000.

4. Gergen PJ, Turkeltaub PC \& Kovar MG. The prevalence of allergic skin test reactivity to eight common aeroallergens in the U.S. population: results from the second National Health and Nutrition Examination Survey.J Allergy ClinImmunol. 1997;80(5):669-679.

5. Zeidler C, Yosipovitch G, Stander $S$. Prurigonodularis and its management. Dermatol Clin. 2018;36(3):189-197.

6. Leung DYM, Eichenfield LF, Boguniewicz M. Atopic dermatitis. In: Wolff K, Goldsmith LA, Katz SI, Gilchrest BA, Paller AS, Leffell $D J$, editors. Fitzpatrick's dermatology in general medicine. 7th ed. New York: McGraw-Hill; 2008.

7. Sik H, Min-Kyung S \& Choong-Rim H. The Efficacy and Safety of Long-term Oral Cyclosporine Treatment for Patients with Atopic Dermatitis. Ann Dermatol. 2010;22(1):9-15.

8. Wu JJ, Huang DB, Pang KR, Hsu S, Tyring SK. Thalidomide: dermatological indications, mechanisms of action and side effects. Br J Dermatol.2005;153:254-273.

9. Michael RL \& Stephen S. Prurigo nodularis: a review. Australasian Journal of Dermatology. 2005;46(4):211-220.

10. Berth-Jones J, Smith SG \& Graham-Brown RAC. Benign familial chronic pemphigus (Hailey-Haileydisease) responds to cyclosporine. Clin Exp Dermatol. 1995;20:70-72.

11. Priya C, Devinder T, Rashmi K. Aging in elderly: chronological versus photoaging. J Am Acad Dermatol. 2012;57(5):343-352.

12. Anon. A consensus report; cyclosporinA therapy for psoriasis. $\mathrm{Br} J$ Dermatol. 1990;122 (Suppl 36):1-3.

13. Fradin MS, Ellis $C N$ \& Voorhees JJ. Efficacy of cyclosporinA in psoriasis: a summary of the United States' experience. Br J Dermatol. 1990;122 (Suppl 36):21-25.

14. Bunikowski R, Staab D, Kussebi F, Brautigam M, Weidinger $\mathrm{G}$, Renz $\mathrm{H}$, et al. Low-dose cyclosporin A microemulsion in children with severe atopic dermatitis: clinical and immunological effects. Pediatr Allergy immunol.2001;12:216-223.

15. Lee SS, Tan AW \& Giam YC. Cyclosporin in the treatment of severe atopic dermatitis: a retrospective study. Ann Acad Med Singapore.2004;33:311-313.

16. Orlando A, Renna $S \&$ Cottone M. Prurigo nodularis of Hyde treated with low-dose thalidomide.Eur Rev Med Pharmacol Sci. 2009;13(2):141-145.

17. Mathews $D$, Mathews $J$ \& Jones NP. Lowdose cyclosporine treatment for sightthreatening uveitis: Efficacy, toxicity, and tolerance. Indian $J$ Opthalmol. 2010;58(1):55-80

18. Ozyazgan Y, Yurdakul S, Yazici H, Tuzun $B$, Iscimen $A$, Tuzun $Y$, et al. Low dose cyclosporine $A$ versus pulsed cyclophosphamide in Behcet's syndrome: a single masked trial. $\mathrm{Br} J$ Ophthlmol. 1992;76:241-243.

19. Mahrle G, Schulze HJ, Färber L, Weidinger G \& Steigleder GK. Low-dose short-term cyclosporine versus etretinate in psoriasis: improvement of skin, nail, and joint involvement. $J \quad A m$ Aca Dermatol. 1995;32:78-88.

20. Harper Jl, Ahmed I, Barclay G, Lacour M, Hoeger $P$, Cork MJ, et al.Cyclosporin for severe childhood atopic dermatitis: short course versus continuous therapy. $\mathrm{Br} J$ Dermatol. 2000;142:52-58.

21. Dorothee S, Thomas AL, Sonja $S$. Antipruritic effect of cyclosporine microemulsion in prurigonodularis: Results of a case series. J Dtsch Dermatol Ges. 2008;12(6):147-149. 